\title{
Successful Treatment of Digital Ischemia Following a Carbon Dioxide Laser and Tourniquet for a Digital Procedure With Adjuvant Low-Level Laser Therapy
}

\author{
Suparuj Lueangarun ${ }^{1 *}$, Therdpong Tempark ${ }^{2}$ \\ 'Division of Dermatology, Chulabhorn International College of Medicine, Thammasat University, Amphur Klongluang, \\ Pathumthani, Thailand 12120 \\ ${ }^{2}$ Department of Pediatrics, Faculty of Medicine, King Chulalongkorn Memorial Hospital, Chulalongkorn University, 1873 \\ Rama 4 Rd., Pathumwan, Bangkok, Thailand 10330
}

\author{
*Correspondence to \\ Suparuj Lueangarun, M.D., MSc.; \\ Division of Dermatology, \\ Chulabhorn International College \\ of Medicine, Thammasat University, \\ Amphur Klongluang, Pathumthani \\ 12120. \\ Tel. +66624625142; \\ Email: saoraya180@gmail.com
}

Published online July 6, 2019

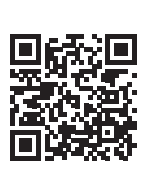

\begin{abstract}
A digital tourniquet with/without epinephrine is commonly used in local anesthetics when operating on digits. However, such a complication as digital ischemia could occur following tourniquet application. We reported an elderly patient with atherosclerotic risk factors and she subsequently underwent a digital tourniquet, partial nail plate removal, and a carbon dioxide laser treatment for subungual wart with digital gangrene development. The successful treatment consisted of wound-dressing, medication, and adjuvant low-level light therapy (LLLT) to enhance the wound healing process, thereby resulting in almost complete recovery of skin color and function of the digit in 3 months. In conclusion, the digital tourniquet should be cautiously applied, especially in elderly patients with atherothrombosis, under minimal pressure and appropriate length of time. Moreover, LLLT could be an effective adjuvant treatment to prevent the vascular complications of the digit.

Keywords: Finger tourniquet; Phalangeal surgery; Digital ischemia; Low-level light therapy.
\end{abstract}

\begin{abstract}
Introduction
A digital tourniquet with/without epinephrine is commonly used in local anesthetics to achieve bloodless field when operating on digits. However, the complications like ischemia and gangrene could occur following the application of a tourniquet. ${ }^{1}$ Currently, low-level light therapy (LLLT) has shown the benefit of wound healing acceleration. $^{2}$
\end{abstract}

\section{Case Report}

An 89-year-old female with underlying diseases of hypertension and dyslipidemia underwent the partial nail plate removal and carbon dioxide laser treatment for subungual wart. The procedures included sterile cleansing, digital nerve block at proximal interphalangeal (PIP) joint using $1 \mathrm{~mL}$ of $2 \%$ xylocaine with adrenaline (1: 200000), and a finger tourniquet using a cut-out finger rubber glove that rolled to the base of the finger. The finger tourniquet was removed after the 10-minute procedure. On the third day after the procedure, the patient developed fusiform violaceous bullous around the left-middle finger (Figure 1A). The aspiration yielded the 3-cc clear yellowish fluid negative for bacterial culture results. On the fifth day, the patient had the gangrene on the tips with bluish discoloration above PIP joint to the digit tip with the sharp demarcation of the tourniquet site.

The patient could move the finger in a full range of motion with minimal pain and numbness following the 2 -second capillary refill of the affected digit. She was then treated with wound-dressing, oral-antibiotics, aspirin 81 mg daily, mupirocin ointment, and isosorbide dinitrate ointment. Furthermore, we also treated the patient with LLLT (Omnilux Revive ${ }^{\mathrm{TM}}$, Phototherapeutics Ltd, Altringham, Manchester, UK), delivering non-coherent red light at a wavelength of $633 \pm 3$ nanometers $(\mathrm{nm})$ and an intensity of $105 \mathrm{~mW} / \mathrm{cm}^{2}$ (a total dose of $126 \mathrm{~J} /$ $\mathrm{cm}^{2}$ after 20 minutes exposure), 3 times per week for 5 weeks to enhance the healing process from the relevant evidence that LLLT could accelerate the healing process of both acute and chronic ulcers, such as diabetic and vasculogenic ulcers. ${ }^{3}$ The improvement was seen after 1 month of therapy with the return of the normal skin color and sensation (Figure 1B). The almost complete recovery of the skin color and function was afterwards observed at 3 months following the wound healing process (Figure 1C).

Please cite this article as follows: Lueangarun S, Tempark T. Successful treatment of digital ischemia following a carbon dioxide laser and tourniquet for a digital procedure with adjuvant low-level laser therapy. J Lasers Med Sci. 2019;10(3):254-256. doi:10.15171/jlms.2019.41. 


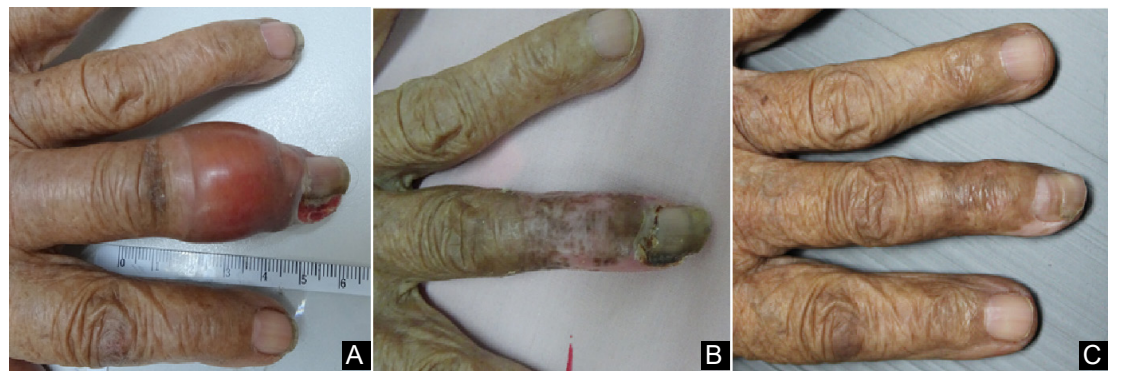

Figure 1. Fusiform violaceous bullous around the left-middle finger (A) and the improvement of normal skin after 1-month (B) and 3-month (C) treatment respectively.

\section{Discussion}

There is concern that that the application of a digital tourniquet, especially in the elderly with atherosclerotic risk factors, should be administered with minimally tight application, widely distributed pressure, and appropriate time of the applied tourniquet. ${ }^{4}$

In our case, despite the short duration of the tourniquet, the atherosclerotic risks of the patient consisted of her advanced age, hypertension, and dyslipidemia. Too high direct pressure of the digital tourniquet could obstruct the superficial digital venous blood flow, causing the superficial necrosis in the fusiform bullous eruption from the applied tourniquet area. Moreover, the direct tourniquet pressure led to direct neuromuscular injury. ${ }^{5,6}$

Despite the traditional wound dressing and topical therapy, we treated the patient with LLLT to enhance the wound healing process, which yielded satisfying treatment results. LLLT emitted the photon to tissue energy exchange which induced the biological activities of the cells change, termed as photobiomodulation or photoactivation without heat or tissue damage. ${ }^{2}$ The proposed principle mechanisms of photobiomodulation were associated with mitochondrial, resulting in the induction of the calcium ion and proton signaling compounds as well as enhanced ATP synthesis. ${ }^{7}$ Moreover, LLLT yielded the benefits in enhancing all phases of wound healing, such as modulated reactive oxygen species, reduction and prevention of apoptosis, induction of transcription factors, stimulation of angiogenesis and vasculogenesis ${ }^{8}$ by increasing growth factors, including vascular endothelial growth factor (VEGF) responsible for the neovascularization necessary for wound healing, and stimulation of cellular activity, ${ }^{9}$ with increased blood flow and improved fibroblasts proliferation and migration, cytokines, growth factors and inflammatory mediator modulation, as well as higher antiapoptotic proteins. ${ }^{2,8,10}$

For the red light, the principle chromophore was the enzyme of the mitochondrial respiratory pathway and cytochrome c oxidase, with major absorption peak about $633 \mathrm{~nm}$ and the activation of mitochondrial respiratory chain components. The $633 \mathrm{~nm}$ wavelength light showed the benefit in enhancing wound healing by the increased procollagen synthesis, accelerated mast cell degeneration, and higher fibroblastic growth factor synthesis from photoactivated macrophages. ${ }^{10,11}$

Currently, the varying clinical applications of LLLT are employed to stimulate wound healing by modulating fibroblast proliferation, attachment, and collagen synthesis. The LLLT applications also decrease pain and inflammation, increase tissue repair, enhance regeneration of different tissues and nerves, and prevent tissue damages of both acute and chronic ulcers, such as herpes zoster wounds, ${ }^{12}$ diabetic $^{3}$ and vasculogenic ulcers, ${ }^{13}$ radiation dermatitis, radiation therapy and infection, scar prevention, ${ }^{14}$ acne vulgaris, ${ }^{15}$ and skin rejuvenation. ${ }^{11}$ Hence, LLLT could be effectively used as an adjuvant to conventional therapy for the improvement of the wound healing process with promising results.

\section{Conclusion}

The digital tourniquet should be cautiously applied under minimal pressure and appropriate length of time, particularly in elderly patients with atherothrombosis. Moreover, low-level laser therapy could potentially be the adjunctive treatment for the prevention of ischemic wound complications of the digit after the digital procedure.

\section{Ethical Considerations}

Written informed consent was obtained from the patient before treatment.

\section{Conflict of Interests}

The authors declare no conflict of interest.

\section{References}

1. Tucker S, Harris PC. The unforgettable finger tourniquet. Injury. 2002;33(1):76-77.

2. Avci P, Gupta A, Sadasivam M, et al. Low-level laser (light) therapy (LLLT) in skin: stimulating, healing, restoring. Semin Cutan Med Surg. 2013;32(1):41-52.

3. Tchanque-Fossuo CN, Ho D, Dahle SE, et al. A systematic review of low-level light therapy for treatment of diabetic foot ulcer. Wound Repair Regen. 2016;24(2):418-426. doi:10.1111/wrr.12399

4. Becerro de Bengoa Vallejo R, Losa Iglesias ME, Lopez DL, et al. Effects of digital tourniquet ischemia: a single center 
study. Dermatol Surg. 2013;39(4):584-592. doi:10.1111/ dsu. 12115

5. Kam PC, Kavanagh R, Yoong FF. The arterial tourniquet: pathophysiological consequences and anaesthetic implications. Anaesthesia. 2001;56(6):534-545.

6. Pedowitz RA. Tourniquet-induced neuromuscular injury. A recent review of rabbit and clinical experiments. Acta Orthop Scand Suppl. 1991;245:1-33.

7. Karu T. Primary and secondary mechanisms of action of visible to near-IR radiation on cells. J Photochem Photobiol B. 1999;49(1):1-17. doi:10.1016/S1011-1344(98)00219-X

8. Corazza AV, Jorge J, Kurachi C, Bagnato VS. Photobiomodulation on the angiogenesis of skin wounds in rats using different light sources. Photomed Laser Surg. 2007;25(2):102-106. doi:10.1089/pho.2006.2011

9. Kipshidze N, Nikolaychik V, Keelan MH, et al. Low-power helium: neon laser irradiation enhances production of vascular endothelial growth factor and promotes growth of endothelial cells in vitro. Lasers Surg Med. 2001;28(4):355364. doi: $10.1002 / 1 \mathrm{sm} .1062$

10. Barolet D. Light-emitting diodes (LEDs) in dermatology. Semin Cutan Med Surg. 2008;27(4):227-238. doi:10.1016/j. sder.2008.08.003

11. Russell BA, Kellett N, Reilly LR. A study to determine the efficacy of combination LED light therapy $(633 \mathrm{~nm}$ and $830 \mathrm{~nm}$ ) in facial skin rejuvenation. J Cosmet Laser Ther. 2005;7(3-4):196-200. doi:10.1080/14764170500370059

12. Park KY, Han TY, Kim IS, Yeo IK, Kim BJ, Kim MN. The Effects of $830 \mathrm{~nm}$ Light-Emitting Diode Therapy on Acute Herpes Zoster Ophthalmicus: A Pilot Study. Ann Dermatol. 2013;25(2):163-167. doi:10.5021/ad.2013.25.2.163

13. Caetano KS, Frade MA, Minatel DG, Santana LA, Enwemeka CS. Phototherapy improves healing of chronic venous ulcers. Photomed Laser Surg. 2009;27(1):111-118. doi:10.1089/pho.2008.2398

14. Park YJ, Kim SJ, Song HS, et al. Prevention of Thyroidectomy Scars in Asian Adults With Low-Level Light Therapy. Dermatol Surg. 2016;42(4):526-534. doi:10.1097/ DSS.0000000000000680

15. Sadick N. A study to determine the effect of combination blue $(415 \mathrm{~nm})$ and near-infrared $(830 \mathrm{~nm})$ lightemitting diode (LED) therapy for moderate acne vulgaris. J Cosmet Laser Ther. 2009;11(2):125-128. doi:10.1080/14764170902777349 